\title{
PEMBERDAYAAN KELOMPOK PERAWATAN DIRI KUSTA (KPD) PUSKESMAS SLAHUNG DALAM PENGEMBANGAN POTENSI PEMBIBITAN TANAMAN BUAH
}

\author{
Mahmudah Hamawi ${ }^{1}$, Alfu Laila ${ }^{2}$, Use Etica ${ }^{3}$, Lutfy Ditya Cahyanti ${ }^{4}$ \\ 1,2,3,4Fakultas Sains dan Teknologi, Universitas Darussalam Gontor \\ Email: lutfyditya@unida.gontor.ac.id
}

\begin{abstract}
The purpose of community service activities with the title Empowerment Group Care (KPD) Leprosy at public healthy Service, District Slahung by potential development fruit nursery, first objective are, to helping public healthy Service, District Slahung as the chief of activities KPD leprosy to increasing the participation rate of leprosy patients in KPD to attend the activities KPD by providing activities pull through the empowerment of leprosy patients in agriculture, especially fruit nurseries. The second objective is to increase the potential of agriculture in the district Slahung especially fruit by empowering KPD Leprosy public healthy Service, District Slahung. To achieve the goals of community service which have conducted the faculty team Agroteknologi Gontor Darussalam University, community service activities carried out in the form of materials, discussion and question and answer, simulation and practice. Once completed community service activities, there was an evaluation. Community service activities are carried out in public healthy Service, District Slahung can be concluded that an increase in the participation of members KPD KPD Leprosy activities. KPD members Leprosy quite interested in community service activities in the field of fruit plant nurseries because most members of the KPD Leprosy is a farmer. The KPD members of both leprosy have been able to carry fruit plant nurseries by grafting and cuttings.
\end{abstract}

Keywords: empowerment, leprosy, nurseries

\begin{abstract}
Abstrak. Tujuan dari kegiatan pengabdian masyarakat dengan judul Pemberdayaan Kelompok Perawatan Diri (KPD) Kusta Puskesmas Slahung Dalam Pengembangan Potensi Pembibitan Tanaman Buah yang pertama adalah membantu puskesmas selaku pelaksana kegiatan KPD kusta dalam meningkatkan angka partisipasi penderita kusta di KPD untuk hadir di kegiatan KPD dengan memberikan kegiatan yang menarik melalui pemberdayaan penderita kusta di bidang pertanian khususnya pembibitan tanaman buah. Tujuan yang kedua adalah meningkatkan potensi pertanian di kecamatan Slahung khususnya tanaman buah dengan memberdayakan kelompok KPD Kusta Puskesmas Slahung. Untuk mencapai tujuan pengabdian masyarakat yang telah dilaksanakan tim dosen Agroteknologi Universitas Darussalam Gontor, kegiatan pengabdian kepada masyarakat dilakukan dalam bentuk pemberian materi, diskusi dan tanya jawab, simulasi serta praktek. Setelah kegiatan pengabdian masyarakat selesai, dilakukan evaluasi. Dari kegiatan pengabdian masyarakat yang dilaksanakan di Puskesmas Slahung di Kecamatan Slahung Kabupaten Ponorogo ini dapat disimpulkan bahwa terjadi peningkatan partisipasi anggota KPD pada kegiatan KPD Kusta. Anggota KPD Kusta cukup tertarik pada kegiatan pengabdian masyarakat dibidang pembibitan tanaman buah karena sebagian besar anggota KPD Kusta adalah petani. Para naggota KPD kusta sudah mampu melaksanakan pembibitan tanaman buah dengan okulasi dan stek.
\end{abstract}

Kata kunci: Pemberdayaan, Kusta, Pembibitan buah 


\section{PENDAHULUAN}

Penyakit kusta adalah salah satu penyakit menular yang dapat menimbulkan masalah yang sangat rumit. Masalah yang dimaksud bukan hanya dari segi medis tetapi meluas sampai masalah sosial, ekonomi dan budaya. Kelompok Perawatan Diri (KPD) yang dibentuk dan dilaksanakan oleh Puskesmas Kecamatan Slahung dianggap efektif dalam mempercepat kesembuhan penderita kusta, karena penderita kusta merasa senasib sehingga mereka tidak segan-segan mengingatkan satu sama lain untuk melakukan pengobatan atau perawatan diri. Dengan kelompok perawatan diri apa yang penderita inginkan dari proses pengobatan yaitu kesembuhan dari penyakit kusta akan berjalan lebih cepat .

Kegiatan KPD Kusta Puskesmas Kecamatan Slahung dilaksanakan 35 hari sekali, bertempat di Puskesmas Kec. Slahung dengan pendampingan dari dokter Puskesmas. Di dalam hal ini, penderita kusta sendiri turut aktif dalam memikirkan, merencanakan, melaksanakan, dan mengevaluasi program-program dalam KPD. Jumlah penderita yang hadir pada saat kegiatan KPD Kusta selalu kurang dari 15, hal tersebut sangat rendah mengingat jumlah penderita kusta yang terdaftar di puskesmas Kec. Slahung sekitar 150 penderita kusta.

Berdasarkan data BPS tahun 2014, diketahui bahwa luas lahan sawah di Kec. Slahung adalah 2165,94 ha dengan luas lahan non sawah adalah 2458,06 ha. Data kependudukan Kec. Slahung tahun 2014 juga menunjukkan bahwa mata pencaharian penduduk secara umum paling banyak adalah sebagai petani pengusaha 13.154 penduduk dan buruh tani 7969 penduduk. Adapun potensi hasil pertanian selain padi dan palawija, yang paling banyak pada tahun 2014 adalah kategori hortikultura berupa cabe besar, cabe rawit, tomat dan terong. Sedangkan untuk potensi tanaman buah di kecamatan Slahung diantaranya alpukat dengan produksi pada tahun 2014 sebesar 840 kuintal, belimbing 104 kuintal, jeruk keprok 2005 kuintal, mangga 21.840 kuintal dan pisang 19.054 kuintal (BPS, 2014). Dari hal tersebut, dapat diketahui bahwa potensi pertanian terutama tanaman buah di kecamatan Slahung sangat besar dan masih bisa dikembangkan lagi.

Tujuan dari kegiatan pengabdian ini yang pertama adalah membantu puskesmas selaku pelaksana kegiatan KPD kusta dalam meningkatkan angka partisipasi penderita kusta di KPD untuk hadir di kegiatan KPD dengan memberikan kegiatan yang menarik melalui pemberdayaan penderita kusta di bidang pertanian khususnya pembibitan tanaman buah. Tujuan yang kedua adalah meningkatkan potensi pertanian di kecamatan Slahung khususnya tanaman buah dengan memberdayakan kelompok KPD Kusta Puskesmas Slahung. Setelah kegiatan pengabdian selesai, penderita kusta dan keluarga diharapkan akan lebih mandiri secara ekonomi dengan bisnis pembibitan tanaman buah sehingga nanti untuk jangka lebih panjang dapat meningkatkan perekonomian di Kecamatan Slahung pada umumnya.

\section{METODE PELAKSANAAN}

Untuk mencapai tujuan pengabdian, kegiatan pengabdian kepada masyarakat dilakukan dalam bentuk pemberian materi, diskusi dan tanya jawab, simulasi serta praktek. Setelah kegiatan pengabdian masyarakat selesai, dilakukan evaluasi. Pemberian materi, diskusi dan tanya jawab dilakukan untuk memberikan gambaran kepada mitra yang merupakan anggota KPD Kusta agar memahami teknologiteknologi pembibitan tanaman buah. Langkah ini diperlukan untuk mempermudah anggota KPD kusta untuk melakukan praktik pembibitan tanaman buah. Adapun kegiatan diskusi dan 
tanya jawab dilakukan untuk memberikan kesempatan mitra bertanya tentang materimateri yang belum jelas. Dalam pengabdian kepada masyarakat ini, anggota KPD kusta juga diberikan kesempatan secara langsung untuk mempraktekkan berbagai metode dan teknik pembibitan tanaman buah. Kriteria keberhasilan kegiatan pengabdian kepada masyarakat ini secara umum adalah anggota KPD kusta terampil dalam melaksanakan pembibitan tanaman buah.

Setelah kegiatan pengabdian selesai, diadakan kegiatan monitoring dan evaluasi. Dengan adanya kegiatan monitoring diharapkan dapat memberi arahan, bimbingan dan pengawasan kegiatan ketika anggota KPD kusta melakukan praktek pembibitan tanaman buah. Evaluasi dilakukan guna memberikan masukan. apabila kegiatan yang dilaksanakan tidak sesuai dengan situasi dan kondisi di lapangan sehingga dapat dilakukan pengen- dalian dan perbaikan sesuai kebutuhan anggota KPD kusta.

\section{HASIL DAN PEMBAHASAN}

Kegiatan pengabdian masyarakat dilaksanakan oleh tim dosen Agroteknologi Fakultas Sains dan Teknologi Universitas Darussalam Gontor. Pengabdian masyarakat diadakan di KPD Kusta Puskesmas Slahung, Kecamatan Slahung, Kabupaten Ponorogo pada bulan JuliOktober 2016. Dari angka partisipasi diketahui bahwa terjadi peningkatan kehadiran anggota KPD Kusta sebelum dilakukan pengabdian dan setelah pengabdian. Hal ini dikarenakan ada ketertarikan dari anggota terhadap materi di bidang pertanian mengingat sebagian besar anggota KPD berprofesi sebagai petani. Sebelum dilaksanakan kegiatan pengabdian, angka partisipasi kehadiran anggota KPD di KPD sangat rendah, karena pertemuan rutin yang diadakan KPD setiap bulannya (35 hari sekali) dirasa monoton.

Tabel 1. Tingkat Kehadiran Anggota KPD Kusta pada Kegiatan KPD Sebelum Program Pengabdian

\begin{tabular}{cclc}
\hline No & Tanggal & \multicolumn{1}{c}{$\begin{array}{c}\text { Materi Oleh Pihak } \\
\text { Puskesmas }\end{array}$} & Jumlah yang hadir \\
\hline 1 & 27 April 2016 & Perawatan diri & 9 \\
\hline 2 & 25 Mei 2016 & Perawatan diri & 9 \\
\hline 3 & 29 Juni 2016 & Perawatan diri & 8 \\
\hline
\end{tabular}

Tabel 2. Tingkat Kehadiran Anggota KPD Kusta pada Kegiatan KPD Setelah Program Pengabdian

\begin{tabular}{cclc}
\hline No & \multicolumn{1}{c}{ Tanggal } & \multicolumn{1}{c}{ Materi Pengabdian } & Jumlah yang hadir \\
\hline 1 & 20 Juli 2016 & Pembibitan tanaman buah dengan okulasi & 11 \\
\hline 2 & 07 Agustus 2016 & $\begin{array}{l}\text { Budidaya tanaman buah dengan } \\
\text { tabulampot }\end{array}$ & 15 \\
\hline 3 & 12 September 2016 & Pembibitan tanaman buah dengan stek & 15 \\
\hline
\end{tabular}


Dalam kegiatan pengabdian kepada masyarakat Pemberdayaan Kelompok Perawatan Diri Kusta (KPD) Puskesmas Slahung dalam Pengembangan Potensi Pembibitan Tanaman Buah, materi yang disampaikan kepada mitra pada pertemuan pertama adalah metode pembibitan tanaman buah dengan metode okulasi. Pada sesi pertemuan ini, juga disampaikan tentang potensi tanaman buah di kecamatan Slahung pada khususnya dan kabupaten Ponorogo pada umumnya. Setelah sesi materi, kemudian dilaksanakan sesi diskusi dimana anggota KPD Kusta antusias bertanya apa yang belum jelas bagi mereka. Berikutnya anggota KPD Kusta yang hadir diberi kesempatan untuk mempratekkan secara langsung pembibitan tanaman buah dengan okulasi. Bahan tanam yang digunakan untuk praktek adalah batang bawah dan batang atas buah jambu biji madu deli dan jambu demak. Mitra yang hadir seluruhnya berperan aktif dalam kegiatan praktek. Batang bawah dan batang atas jambu disediakan oleh tim dosen Agroteknologi Fakultas Sains dan Teknologi Universitas Darussalam Gontor.

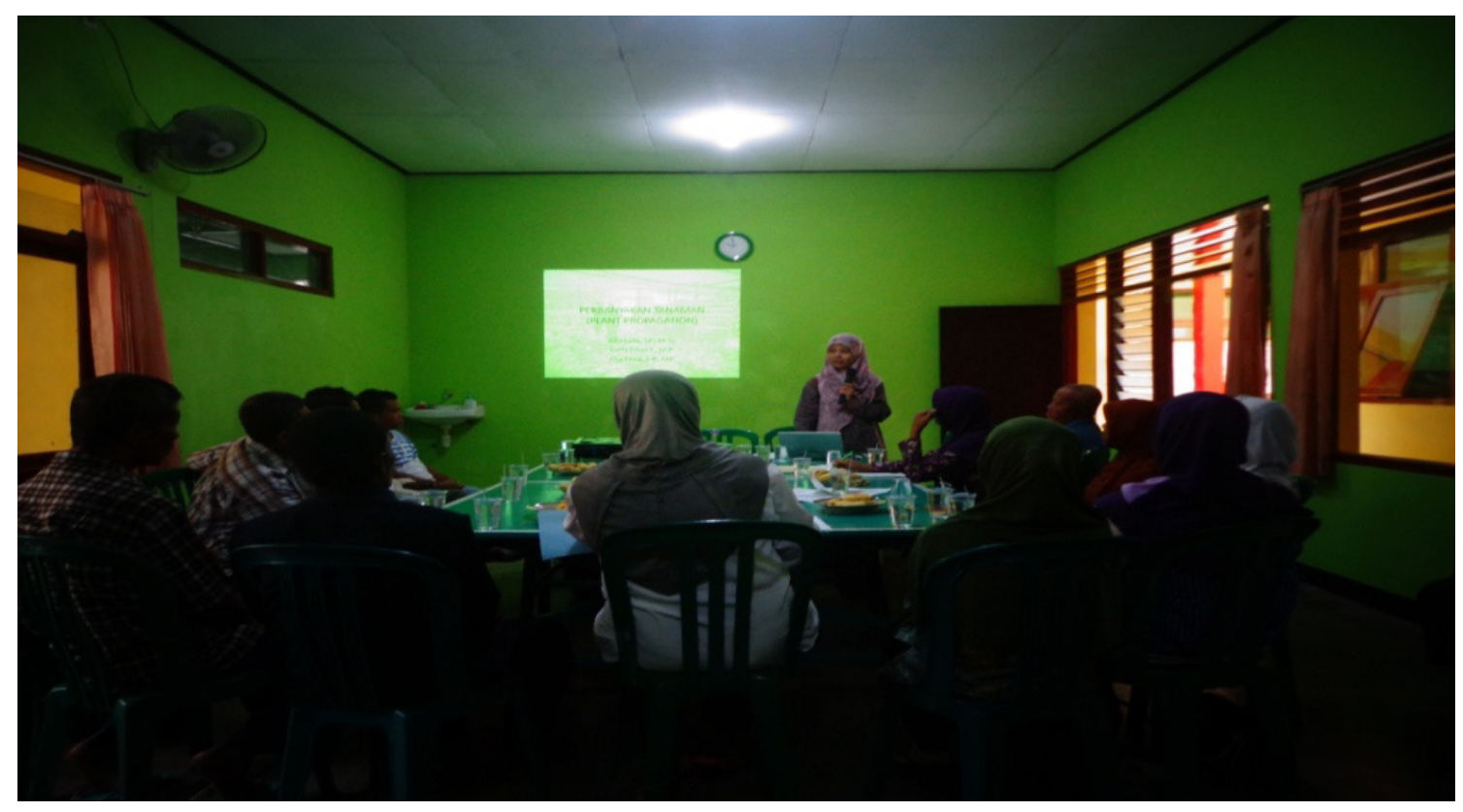

Gambar 1. Pemberian materi okulasi

Agar tingkat keberhasilan tinggi kriteria tanaman yang akan dijadikan batang bawah ialah mampu beradaptasi atau tumbuh kompak dengan batang atasnya, tanaman dalam kondisi sehat, sistem perakarannya baik dan dalam serta tahan terhadap keadaan tanah yang kurang menguntungkan, termasuk hama dan penyakit yang ada dalam tanah. Serta tidak mengurangi kualitas dan kuantitas buah pada tanaman yang sudah disambungkan/diokulasi (Prastowo, et 2006). Untuk batang atas kriteria yang harus dipenuhi agar tingkat keberhasilan tinggi adalah mampu beradaptasi atau tumbuh kompak dengan batang bawahnya, sehingga batang atas ini mampu menyatu dan dapat berproduksi dengan optimal, cabang dari pohon yang sehat, pertumbuhannya normal dan bebas dari serangan hama dan penyakit dan cabang berasal dari pohon induk yang sifatnya benarbenar yang seperti dikehendaki, misalnya berbuah lebat dan berkualitas tinggi (Prastowo, et al. 2006). 


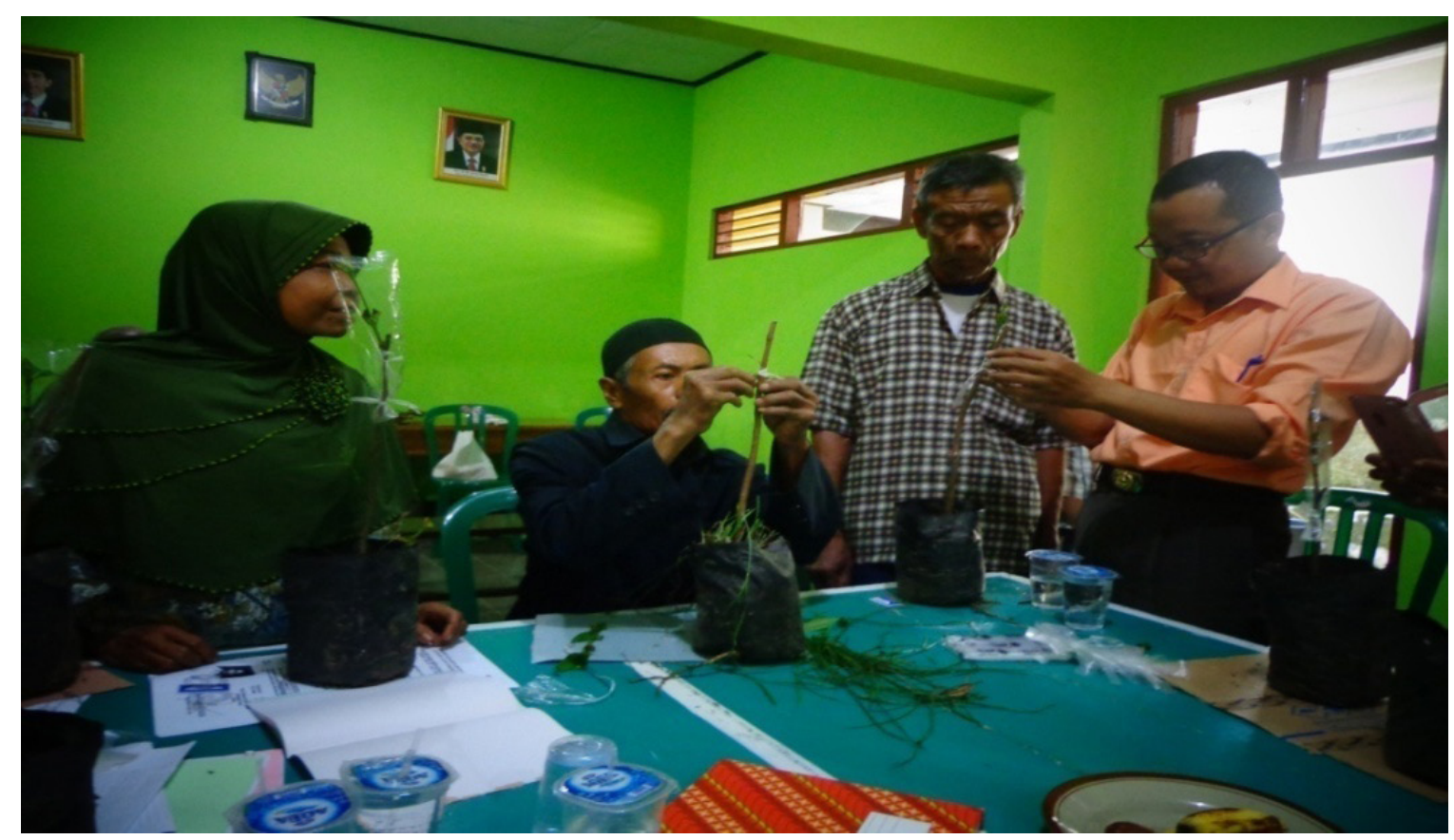

Gambar 2. Praktek Grafting

Pada pertemuan kedua materi yang disampaikan oleh pengabdi kepada anggota KPD Kusta selaku mitra adalah perbanyakan tanaman buah dengan metode tabulampot. Pada sesi ini mitra diberi kesempatan untuk kembali mempraktekkan perbanyakan tanaman buah dengan okulasi untuk mengevaluasi tingkat keberhasilan materi okulasi yang telah disampaikan pada pertemuan sebelumnya. Dari 15 anggota KPD yang mempratekkan okulasi, baru 3 yang berhasil melakukan okulasi. Kegagalan sambungan ditandai dengan tidak munculnya tunas pada batang atasyang digunakan, dan tunas-tunas baru yang muncul berasal dari batang bawah. Riodevizo (2010) menyebutkan bahwa kegagalan ini disebabkan oleh tidak terbentuknya saluran pembuluh xylem dan floem untuk mengalirkan air dan hara ke bagian batang atas. Tunas yang muncul dari batang bawah merupakan mekanisme untuk tetap bertahan hidup tumbuhan guna menggantikan batang atas yang telah dipotong. Hartman et al. (1990) mengemukakan bahwa keberhasilan sambungan salah satunya dipengaruhi oleh kesesuaian antara batang atas dan batang bawah untuk menyatukan diri. Tahapan terjadinya kompatibilitas penyambungan diawali dengan terbentuknya sel-sel parenkim yang akan menghubungkan jaringan batang atas dengan jaringan batang bawah kemudian kalus terdeferensiasi menjadi jaringan pengangkut (phloem dan xylem). Kompatibilitas penyambungan terjadi apabila jaringan pengangkut tersebut dapat berfungi secara baik untuk menghubungkan jaringan bawah dengan batang (Pina dan Errea, 2005). 


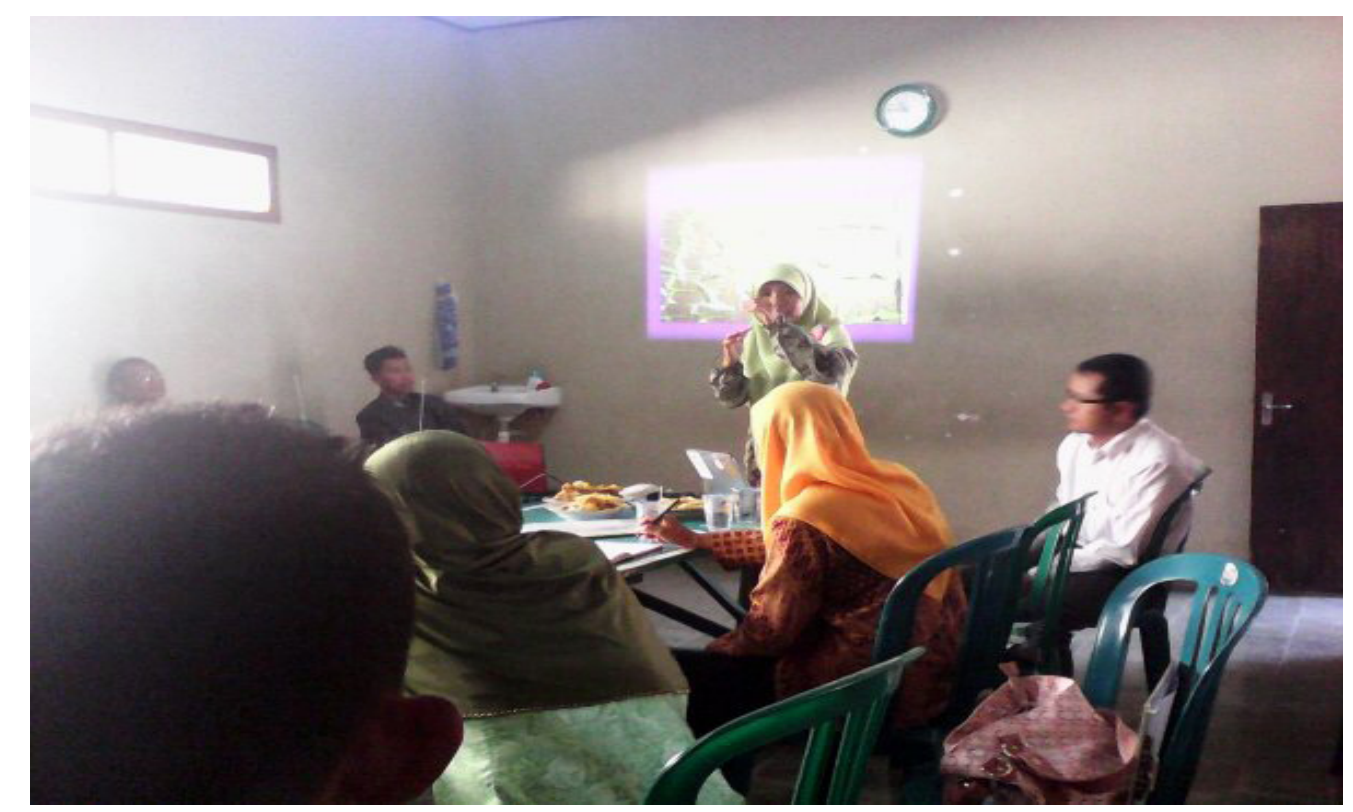

Gambar 3. Pemberian Materi Tabulampot

Untuk materi tabulampot, materi yang diberikan adalah tentang budidaya tanaman buah dalam pot untuk jambu madu deli. Sistem budidaya secara tabulampot (tanaman buah dalam pot) banyak digunakan untuk membudidayakan jambu madu deli. Dengan sistem ini, jambu madu deli lebih cepat dibandingkan ditanam langsung ke tanah yaitu 8 bulan. Sehingga petani lebih memilih membudidayakan secara tabulampot dibandingkan ditanam langsung ketanah. Walaupun sudah dibudidayakan dengan sistem tabulampot, tetapi dilapangan banyak dijumpai tanaman yang belum berbuah meskipun sudah berumur diatas 8 bulan. Hal ini dikarenakan pertumbuhan tanaman masih mengarah ke pertumbuhan vegetatif dan belum memasuki masa generatifnya (Tarigan, et al. 2015).

Pada pertemuan ketiga, materi yang adalah bagaimana cara membudidayakan tanaman buah dengan stek. Contoh yang menjadi bahan praktek adalah tanaman buah naga. Setiap anggota yang hadir mendapatkan bahan praktek untuk kemudian dipraktekan bagaimana melakukan budidaya tanaman buah naga dengan stek. Buah naga dapat diper- banyak secara vegetatif dan generatif. Sistem perbanyakan secara vegetatif dan generatif mempunyai kelebihan dan kelemahan masingmasing.Namun dalam praktiknya, orang lebih cenderung melakukan perbanyakan secara vegetatif(Andrina, 2009). Pada pertemuan berikutnya dilakukan evaluasi untuk memastikan bahawa anggota KPD sudah mampu dalam melakukan budidaya tanaman buah naga dengan stek. Anggota KPD sangat antusias dalam mengikuti kegiatan materi ataupun praktek.

Kegiatan monitoring dan evaluasi dilakukan dengan memantau tingkat keberhasilan okulasi dan stek dari anggota KPD kusta. Bila ada anggota yang belum terampil, dilakukan kegiatan praktek secara berulang-ulang sampai anggota tersebut terampil kemudian bibit hasil okulasi bisa tumbuh dengan baik.

\section{SIMPULAN DAN SARAN}

Terjadi peningkatan partisipasi anggota KPD pada kegiatan KPD Kusta. Anggota KPD Kusta cukup tertarik pada kegiatan pengabdian masyarakat dibidang pembibitan tanaman buah karena sebagian besar anggota KPD Kusta 
adalah petani. Para anggota KPD kusta sudah mampu melaksanakan pembibitan tanaman buah dengan okulasi dan stek.

\section{DAFTAR PUSTAKA}

BPS. 2014. Ponorogo Dalam Angka. www. bps.go.id

Prastowo., James M. Roshetkhe., Gerhard E.S Maurung., Erry Nugaraha., Joel M. Tukan., Fransiskus Harum. 2006. Teknik Pembibitan dan Perbanyakan Vegetatif Buah. ICRAF. Bogor

Riodevizo. 2010. Pengaruh Umur Pohon Induk terhadap Keberhasilan Stek dan Sambungan Shorea selanica BI. Departemen Silvikultur. Fakultas Kehutanan Institut Pertanian Bogor. Bogor

Hartman, H.T.; D.E. Kester and F.T. Davies. 1990. Plant Propagation Principles and
Practic. Fifth Edition. Prentice Hall International Inc., Englewood Cliffs. New Jersey.

Pina, A. and P. Errea. 2005. A review of new advances in mechanism of graft compatibility-incompatibility. Scientia Horticulturae, 106, 1-11.

Tarigan., Chairani Hanum, Revandy I M Damanik. 2015. Pertumbuhan Vegetatif dan Generatif Jambu Air (Syzygium samarangense (Blume) Merr. \& Perry) Varietas Deli Hijau dengan Perlakuan ZPT dan Media Tanam. Jurnal Online Agroekoteknologi. 3 (2): 740-747.

Andrina, Y., 2009. Pengaruh Beberapa Zat Pengatur Tumbuh Terhadap Pertumbuhan Setek Tanaman Buah Naga Berdaging Merah (Hylocereus costaricensis (Web) Britton \& Ross). Skripsi. Universitas Andalas, Padang. 